\title{
The analysis of sacrum and coccyx length measured with computerized tomography images depending on sex
}

\author{
Rukiye Sumeyye Bakici ${ }^{1}$, Zulal Oner ${ }^{1 *}$ and Serkan Oner $^{2}$ (D)
}

\begin{abstract}
Background: Sex estimation is vital in establishing an accurate biological profile from the human skeleton, as sex influences the analysis of other elements in both Physical and Forensic Anthropology and Legal Medicine. The present study was conducted to analyze the sex differences between the sacrum and coccyx length based on the measurements calculated with computed tomography (CT) images. One hundred case images (50 females, 50 males) who were between the ages of 25 and 50 and admitted by the emergency department between September 2018 and June 2019 and underwent CT were included in the study. Eighteen lengths, 4 curvature lengths, and 2 regions were measured in sagittal, coronal and transverse planes with orthogonal adjustment for three times.

Results: It was stated that the mean anterior and posterior sacral length, anterior and posterior sacrococcygeal length, anterior and posterior sacral curvature length, anterior coccygeal curvature length, sacral area, lengths of transverse lines 1, 2, 3 and 4, sacral first vertebra transverse and sagittal length measurements were longer in males when compared to females $(p<0.05)$. It was noted that the parameter with the highest discrimination value in the receiver operating characteristic $(\mathrm{ROC})$ analysis was the sacral area (AUC $=0.88 / \mathrm{Acc}=0.82$ ). Based on Fisher's linear discriminant analysis findings, the discrimination rate was $96 \%$ for males, $92 \%$ for females and the overall discrimination rate was $94 \%$.
\end{abstract}

Conclusions: It was concluded that the fourteen parameters that were indicated as significant in the present study could be used in anthropology, Forensic Medicine and Anatomy to predict sex.

Keywords: Computerized tomography, Sex estimation, Coccyx, Sacrum, Linear discriminant analysis

\section{Highlights}

- Eighteen lengths, 4 curvature lengths and 2 regions were measured in sagittal, coronal and transverse planes with orthogonal adjustment for three times.

- The sacrum and coccyx are used for sex identification.

- The sacral area was greater in males.

- The total rate of Fisher's linear discriminant analysis is 0.94 .

\footnotetext{
* Correspondence: zulaloner@karabuk.edu.tr

${ }^{1}$ Faculty of Medicine Department of Anatomy, Karabuk University, Karabuk, Turkey

Full list of author information is available at the end of the article
}

\section{Background}

One of the most important problems faced by Forensic Medicine specialists is the estimation of biological identity depending on the skeletal remains of an unidentified individual (Singh and Pathak 2013; Torimitsu et al. 2018). The ancestry, sex, age, and height of the individual should be known to determine the biological identity in Forensic Medicine and Archeology (Chiba et al. 2018; Karakas et al. 2011). The estimation of the sex is the first step (Gaya-Sancho et al. 2018; Torimitsu et al. 2017; Zhan et al. 2018). Osteometry standards vary depending on parameters such as genetics, environmental factors, and sex dimorphism associated with the profession and lifestyle in the estimation of the sex. Generally, female bones and body size are known to be smaller when 
compared to males. The degree of the difference may vary within the same population or between populations and could lead to secular variations (Hemy et al. 2013; Macaluso and Lucena 2014; Singh and Pathak 2013; Zhan et al. 2018).

In the literature, various studies were conducted on hand and foot (Case and Ross 2007), tibia (Šlaus et al. 2013), patella (Michiue et al. 2018), femur (Curate et al. 2016), pelvis (Torimitsu et al. 2015), radius and ulna (Issa et al. 2016), scapula and clavicle (Papaioannou et al. 2012), sternum and 4th costa (Ramadan et al. 2010), first cervical vertebra (Marino 1995), second cervical vertebra (Marlow and Pastor 2011), skull (Ekizoglu et al. 2016) bones using different methods. Bones could be damaged, or they could be missing. Thus, it is necessary to identify the sex depending on various bones (Zech et al. 2012).

The accuracy of sex estimation depends on the difference in the analyzed skeletal components between the sexes and the capability of the techniques employed to define the differences in shape and length (Gonzalez et al. 2009). Morphological, metric, geometric morphometric, and probabilistic methods are used in sex estimation. It is easier to analyze and interpret numerical data available with metric methods (Krishan et al. 2016). Metric measurements conducted with computerized tomography (CT) could also be utilized in reconstructive identification, comparative bone, and lesion recognition (Dedouit et al. 2014). It allows systematization and re-evaluation of traditional anthropological methods in Forensic Medicine and provides precise and accurate sex estimation in modern populations. Although the method is expensive, it provides encouraging results since it could be repeated (Grabherr et al. 2009; Krishan et al. 2016).

The present study aimed to specify the correlation between the metric sacrum and coccyx parameters, and their availability for sex estimation with orthogonal plane adjusted CT images, and to compare the findings in different populations.

\section{Methods}

\section{The study population}

The images of individuals who were $25-50$ years old during their admission to the emergency department between September 2018 and June 2019 and underwent CT were reviewed. Among these individuals, 100 cases (50F, 50M) with normal CT appearance were selected randomly. Those with significant degenerative diseases, bone pathologies, or surgical history were excluded from the study. The study was approved by the Non-Interventional Clinical Research Ethics Committee on 25/09/2019 with the protocol no: 6/10.
Multidetector computerized tomography (MDCT) protocol All images were obtained with the CT scans conducted with a 16-slice MDCT scanner (Aquilion 16; Toshiba Medical Systems, Tokyo, Japan). All images were scanned in a supine position at $3 \mathrm{~mm}$ slice thickness.

\section{Image analysis}

All measurements were conducted on a workstation (Horos, Version 3.3, USA). The axial plane images were analyzed with two and three dimensional reconstructions (Multi Planar Reconstruction-MPR, Maximum Intensity Projection-MIP) using a standard bone window. Images that were focused on the sacrum with standard magnification were adjusted to the orthogonal plane in three planes. Length and area measurements were conducted on the sacrum and coccyx.

In the orthogonal plane, anatomical points are determined in 3 planes, and planes are brought to these points. All parameters are measured with reference to this plane (Oner et al. 2019). The orthogonal plane axes were aligned to pass through the promontory in the sagittal image series, the corpus vertebrae in the coronal image series, and both the vertebral spinous process and the symphysis pubis in the axial image series (Fig. 1). In order to minimize observer errors, measurements were made three times at different times by the same observer, and the arithmetic mean of these three measurements was used in the calculations.

Eighteen length, 4 curvature length, and 2 area measurements were conducted on three planes, to obtain 3 measurements for 24 parameters, and length measurements were recorded in $\mathrm{cm}$ and areas in $\mathrm{cm}^{2}$.

Four length, 4 curvature length, and 2 area measurements were conducted on the sagittal plane. These images were adjusted to the orthogonal plane and the measurements were conducted depending on the parameter details presented in Table 1 (Fig. 2).

To observe the anterior sacral foramina clearly in the measurements conducted on the coronal image series, the length measurements were conducted by increasing the MIP after the adjustment to the orthogonal plane (Table 2, Fig. 3).

The measurements were conducted on the axial series with increased MIP to observe the distance between the anterior sacral width (ASW) and the leftright auricular surface (LRFA-S). The sagittal (S1-S) and transverse length (S1-T) measurements of the sacral 1st vertebra measurements were conducted by increasing the section thickness until the most lateral transverse edges of the base of the sacrum were clearly visible, depending on the parameter details presented in Table 3 (Fig. 4). 


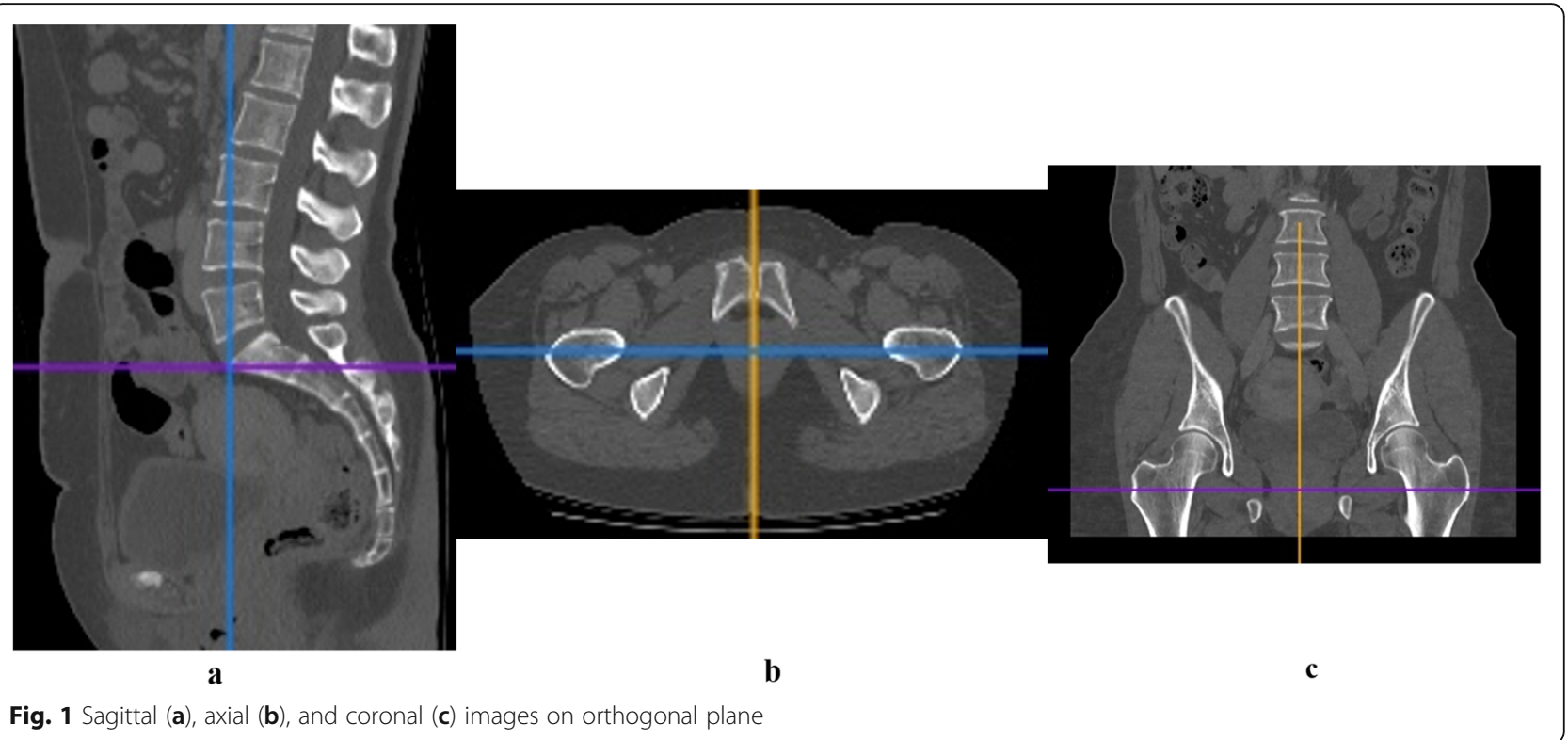

\section{Statistical analysis}

Data analysis was conducted with Minitab 17 statistics software in the study. The Anderson-Darling, a normality test, was applied for all data. Two sample $\mathrm{T}$ test was conducted on data with normal distribution. In the nonparametric analysis method, the Mann-Whitney U test was conducted on data without normal distribution ( $\mathrm{p} \leq$ 0.05). Receiver operating characteristic (ROC) analysis was conducted with SPSS 21 to remark the significance of the variables in sex estimation. ROC analysis was used to remark the optimum values for sex estimation. Measurements were observed by an experienced radiologist. Measurements were made by observing 100 cases 3 times at different times. Therefore, technical measurement error (TEM), relative technical measurement error (rTEM), and reliability coefficient (R) were calculated for intraobserver error analysis. Since measurements were observed by a radiologist, the inter-observer error could not be calculated. Calculations are made in Microsoft Excel. The values for the reliability coefficient range

Table 1 Sagittal plane measurements

\begin{tabular}{|c|c|}
\hline Parameters & Details \\
\hline Anterior sacral length (ASL) & The distance between sacrum promontory and the 5th sacral vertebra anterior-inferior \\
\hline Posterior sacral length (PSL) & $\begin{array}{l}\text { The distance between 1st sacral vertebra posterior- superior of the sacrum and the } 5 \text { th sacral vertebra } \\
\text { anterior-inferior }\end{array}$ \\
\hline $\begin{array}{l}\text { Anterior sacrococcygeal length } \\
(\mathrm{ASCL})\end{array}$ & $\begin{array}{l}\text { The distance between the 1st sacral vertebra anterior-superior of the sacrum and the last coccygeal vertebra } \\
\text { anterior-inferior }\end{array}$ \\
\hline $\begin{array}{l}\text { Posterior sacrococcygeal length } \\
\text { (PSCL) }\end{array}$ & $\begin{array}{l}\text { The distance between the 1st sacral vertebra posterior-superior of the sacrum and the last coccygeal vertebra } \\
\text { anterior-inferior }\end{array}$ \\
\hline Anterior sacral curvature length (ASC) & The curvature length between sacrum promontory and the end of the 5th sacral vertebra \\
\hline $\begin{array}{l}\text { Posterior sacral curvature length } \\
\text { (PSC) }\end{array}$ & The curvature length between the sacrum posterior-superior and 5th sacral vertebra posterior-inferior \\
\hline $\begin{array}{l}\text { Anterior coccygeal curvature length } \\
\text { (ACC) }\end{array}$ & The curvature length between the coccyx anterior- superior and 5th sacral vertebra anterior-inferior \\
\hline $\begin{array}{l}\text { Posterior coccygeal curvature length } \\
\text { (PCC) }\end{array}$ & The curvature length between coccyx posterior- superior and 5th sacral vertebra posterior-inferior \\
\hline Sacral area (SA) & The sacrum area between the beginning of the 1st sacral vertebra and the end of the 5th sacral vertebra \\
\hline Coccygeal area (CA) & $\begin{array}{l}\text { The coccyx area between the beginning of the 1st coccygeal vertebra and the end of the last coccygeal } \\
\text { vertebra }\end{array}$ \\
\hline
\end{tabular}




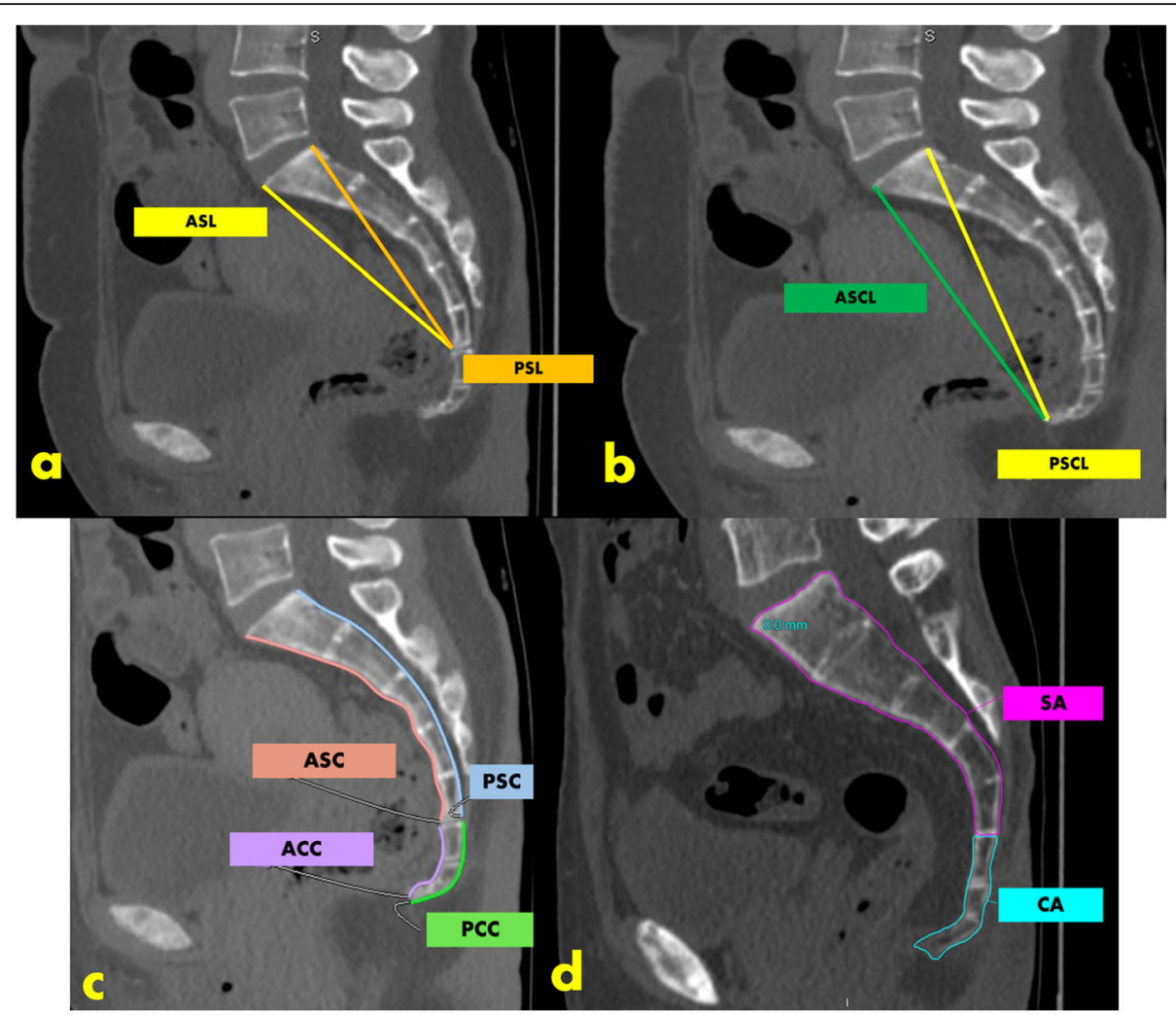

Fig. 2 a Anterior (ASL) and posterior sacral length (PSL) measurement on the sagittal plane. b Anterior (ASCL) and posterior sacrococcygeal length (PSCL) measurement on the sagittal plane. $\mathbf{c}$ Anterior sacral curvature length (ASC) and posterior sacral curvature length (PSC), anterior coccygeal curvature length (ACC), and posterior coccygeal curvature length (PCC) measurement on the sagittal plane. $\mathbf{d}$ Sacral (SA) and coccygeal area (CA) measurement on the sagittal plane

from 0 to 1 . A reliability coefficient value of below 0 indicates "no reliability," $\mathrm{R}$ value $>0$ to $<0.2$ is slight reliability, $0.2-<0.4$ is fair reliability, $0.4-<0.6$ is moderate, $0.6-<0.8$ is substantial, and $0.8-1.0$ is almost perfect reliability (Jamaiyah et al. 2010; Perini et al. 2005). The overall significance of the variables was determined with Fisher's linear discriminant analysis (FDA). Discriminant function analysis is one of the most widely used statistical methods in sex estimation studies, which provides an estimation of sex by evaluating two or more variables simultaneously. Wilks lambda values were calculated to determine how well each function classified individuals into male and female groups (Etli et al. 2019). Lambda values highlight different group averages of near-zero

Table 2 Coronal plane measurements

\begin{tabular}{ll}
\hline Parameters & Details \\
\hline Length of transverse line 1 (LTL-1) & The distance between the most lateral points on sacrum transverse line 1 \\
Length of transverse line 2 (LTL-2) & The distance between the most lateral points on sacrum transverse line 2 \\
Length of transverse line 3 (LTL-3) & The distance between the most lateral points on sacrum transverse line 3 \\
Length of transverse line 4 (LTL-4) & The distance between the most lateral points on sacrum transverse line 4 \\
Right interforaminal height-1 (IFHR-1) & The shortest distance between the right 1st pelvic sacral foramina and right 2nd pelvic sacral foramina \\
Right interforaminal height-2 (IFHR-2) & The shortest distance between the right 2nd pelvic sacral foramina and right 3rd pelvic sacral foramina \\
Right interforaminal height-3 (IFHR-3) & The shortest distance between the right 3rd pelvic sacral foramina and right 4th pelvic sacral foramina \\
Left interforaminal height-1 (IFHL-1) & The shortest distance between the left 1st pelvic sacral foramina and left 2nd pelvic sacral foramina \\
Left interforaminal height-2 (IFHL-2) & The shortest distance between the left 2nd pelvic sacral foramina and left 3rd pelvic sacral foramina \\
Left interforaminal height-3 (IFHL-3) & The shortest distance between the left 3rd pelvic sacral foramina and left 4th pelvic sacral foramina \\
\hline
\end{tabular}




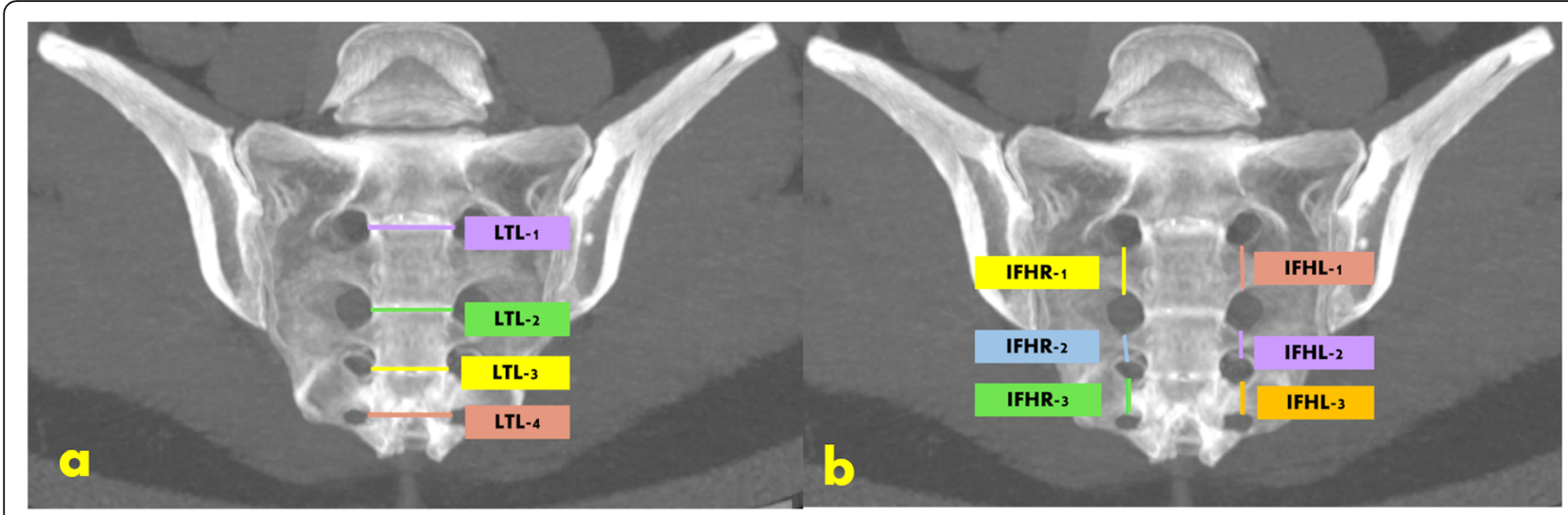

Fig. 3 a The measurement of the lengths transverse lines 1, 2, 3, and 4 on coronal plane. $\mathbf{b}$ The measurement of the right interforaminal height 1, 2, and 3 (IFHR-1, 2, and 3) and left interforaminal height 1, 2, and 3 (IFHL-1, 2, and 3) on the coronal plane

values and similar group averages of near-one values (Torimitsu et al. 2017). P values $<0.05$ were considered to indicate statistical significance.

\section{Results}

The reliability coefficient $(\mathrm{R})$ ranges between 0.71 and 1.00 in intra-observer error analysis (from substantial to perfect). Ratios show that intraobserver error is at an acceptable level. Table 4 shows the results for each variable.

The mean age of the male participants was $40 \pm 7.84$ and the mean age of female participants was $42.2 \pm 7.13$. The ages of females and males were analyzed with the AndersonDarling test and it was demonstrated that the data distribution was normal. Mann Whitney $U$ test findings revealed that there was no significant difference between the mean age of male and female individuals $(\mathrm{p}>0.26)$.

ASL, ASCL, PSCL, ASC, PSC, ACC, LTL-1, LTL-2, LTL-3, IFHR-3, IFHL-2, IFHL-3, S1-T, S1-S, LRFA-S, and ASW parameters were analyzed with the AndersonDarling test, and it was determined that the data distribution was normal. The two sample $\mathrm{T}$ test revealed a significant difference between ASL, PSL, ASCL, PSCL, ASC, PSC, ACC, LTL-1, LTL-2, LTL-3, S1-T, and S1-S parameters depending on sex, and the findings were longer in males when compared to females $(\mathrm{p}<0.05)$. No significant difference was observed between the PCC, IFHR-3, IFHL-2, IFHL-3, LRFA-S, and ASW parameters depending on sex $(p>0.05)$ (Tables 5 and 6).
PSL, SA, CA, LTL-4, IFHR-1, IFHR-2, and IFHL-1 parameters were analyzed with the Anderson-Darling test, and it was defined that the data were not distributed normally. The Mann-Whitney $U$ test results demonstrated a significant difference between PSL and LTL-4 parameters depending on sex, and it was found that the results were longer in males when compared to females. It was observed that SA was greater in males $(\mathrm{p}<0.05)$. No significant difference was determined between CA, IFHR-1, IFHR-2, and IFHL-1 parameters depending on sex $(\mathrm{p}>0.05)$ (Table 5).

ROC analysis results demonstrated that ASL, PSL, ASCL, PSCL, ASC, PSC, ACC, PCC, SA, CA, LTL-1, LTL-2, LTL-3, LTL-4, IFHR-1, IFHR-2, IFHR-3, IFHL-1, IFHL-2, IFHL-3, LRFA-S, $\mathrm{S}_{1}-\mathrm{S}, \mathrm{S}_{1}-\mathrm{T}$, and ASW parameter values were between 0.5 and 1 . It was observed that the highest AUC was for SA (0.88). Thus, the sensitivity (sen) of SA was 0.80 , its specificity (spe) was 0.85 , and accuracy (acc) was 0.82 . The lowest AUC was determined for IFHL-1 (0.51). IFHL-1 sen was 0.42 , spe was 0.48 , and acc was 0.45 (Tables 7, 8, and 9; Fig. 5).

In Fisher's linear discriminant analysis conducted with 24 parameters, it has come to the conclusion that the discrimination power for males was $96 \%$, and the discrimination power for females was $92 \%$ and total discrimination power was $94 \%$ (Tables 10 and 11).

In cross-validation, each state is classified with functions derived from all states except this case. The analysis is therefore performed several times, excluding one

Table 3 Axial plane measurements

\begin{tabular}{ll}
\hline Parameters & Details \\
\hline The distance between the left and right auricular surface (LRFA-S) & The most lateral distance between the left and right auricular surface \\
1st sacral vertebra transverse length (S1-T) & The most lateral transverse distance on 1st sacral vertebra \\
1st sacral vertebra sagittal length (S1-S) & The most lateral sagittal distance on 1st sacral vertebra \\
Anterior sacral width (ASW) & The most lateral anterior distance between the sacrum auricular surface.
\end{tabular}




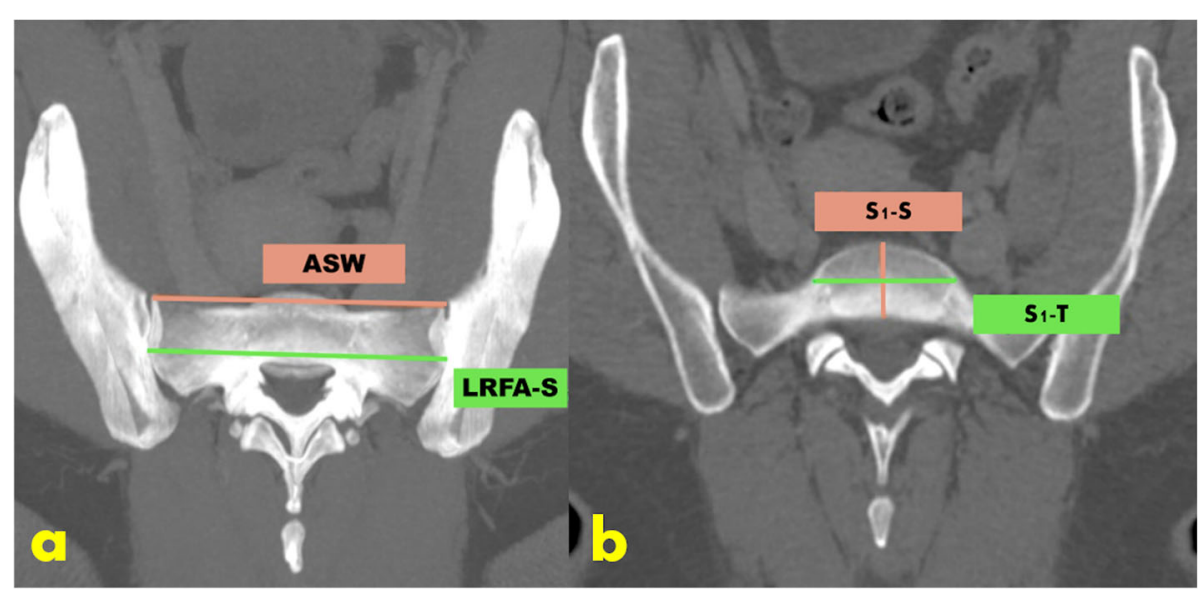

Fig. 4 a The measurement of the distance between anterior sacral width (ASW) and left-right auricular surface (LRFA- S) on axial plane. b The measurement of the sagittal (S1-S) and transverse (S1-T) length of sacral 1st vertebra on the axial plane

Table 4 The intra-observer error analysis in this study $(n=100)$

\begin{tabular}{|c|c|c|c|}
\hline Parameters & TEM & rTEM & $\mathrm{R}$ \\
\hline$\overline{A S L}$ & 0.13 & 1.24 & 0.98 \\
\hline PSL & 0.15 & 1.36 & 0.97 \\
\hline $\mathrm{ASCL}$ & 0.15 & 1.20 & 0.99 \\
\hline PSCL & 0.13 & 0.97 & 0.99 \\
\hline ASC & 0.20 & 1.71 & 0.95 \\
\hline PSC & 0.23 & 1.97 & 0.95 \\
\hline $\mathrm{ACC}$ & 0.19 & 5.45 & 0.91 \\
\hline PCC & 0.24 & 5.47 & 0.89 \\
\hline SA & 0.47 & 2.34 & 0.98 \\
\hline$C A$ & 0.33 & 8.96 & 0.82 \\
\hline LTL-1 & 0.09 & 3.15 & 0.92 \\
\hline LTL-2 & 0.10 & 3.53 & 0.89 \\
\hline LTL-3 & 0.10 & 3.93 & 0.85 \\
\hline LTL-4 & 0.11 & 4.30 & 0.91 \\
\hline IFHR-1 & 0.10 & 7.52 & 0.79 \\
\hline IFHR-2 & 0.10 & 11.93 & 0.83 \\
\hline IFHR-3 & 0.09 & 9.70 & 0.76 \\
\hline IFHL-1 & 0.11 & 7.77 & 0.84 \\
\hline IFHL-2 & 0.09 & 11.10 & 0.78 \\
\hline IFHL-3 & 0.08 & 8.79 & 0.71 \\
\hline LRFA-S & 0.12 & 1.07 & 0.96 \\
\hline$S_{1}-T$ & 0.15 & 2.66 & 0.92 \\
\hline$S_{1}-S$ & 0.09 & 3.07 & 0.95 \\
\hline ASW & 0.12 & 1.08 & 0.98 \\
\hline
\end{tabular}

TEM technical error of measurement, $r T E M$ relative technical error of measurement, $R$ coefficient of reliability, ASL anterior sacral length, PSL posterior sacral length, ASCL anterior sacrococcygeal length, PSCL posterior sacrococcygeal length, $A S C$ anterior sacral curvature length, $P S C$ posterior sacral curvature length, $A C C$ anterior coccygeal curvature length, $P C C$ posterior coccygeal curvature length, $S A$ sacral area, $C A$ coccygeal area, $L T L$ lengths of transverse lines, IFHR right interforaminal height, IFHL left interforaminal height, LRFA-S the distance between the left and right auricular surface, S1-S, S1-Tfirst. sacral vertebra sagittal and transverse length, ASW anterior sacral width
Table 5 The comparison of the mean values of the parameters that exhibited normal distribution

\begin{tabular}{|c|c|c|c|}
\hline Parameters & $\begin{array}{l}\text { Female } \\
\text { Mean } \pm \text { SD }\end{array}$ & $\begin{array}{l}\text { Male } \\
\text { Mean } \pm \text { SD }\end{array}$ & $P^{t-t e s t}$ \\
\hline ASL & $10.55 \pm 0.90$ & $11.03 \pm 0.99$ & $0.01^{*}$ \\
\hline ASCL & $11.98 \pm 1.24$ & $12.83 \pm 1.43$ & $0.00^{*}$ \\
\hline PSCL & $12.72 \pm 0.10$ & $13.77 \pm 1.34$ & $0.00^{*}$ \\
\hline ASC & $11.54 \pm 0.68$ & $12.17 \pm 0.94$ & $0.00^{*}$ \\
\hline PSC & $11.31 \pm 0.78$ & $12.05 \pm 1.08$ & $0.00^{*}$ \\
\hline $\mathrm{ACC}$ & $3.35 \pm 0.58$ & $3.60 \pm 0.64$ & $0.04^{*}$ \\
\hline PCC & $4.22 \pm 0.57$ & $4.46 \pm 0.79$ & 0.10 \\
\hline LTL-1 & $2.80 \pm 0.28$ & $3.00 \pm 0.35$ & $0.00^{*}$ \\
\hline LTL-2 & $2.66 \pm 0.23$ & $2.93 \pm 0.28$ & $0.00^{*}$ \\
\hline LTL-3 & $2.50 \pm 0.20$ & $2.78 \pm 0.24$ & $0.00^{*}$ \\
\hline IFHR-3 & $0.89 \pm 0.17$ & $0.92 \pm 0.18$ & 0.49 \\
\hline IFHL-2 & $0.85 \pm 0.19$ & $0.86 \pm 0.20$ & 0.70 \\
\hline IFHL-3 & $0.90 \pm 0.13$ & $0.95 \pm 0.16$ & 0.13 \\
\hline LRFA-S & $11.46 \pm 0.55$ & $11.36 \pm 0.72$ & 0.46 \\
\hline$S_{1}-S$ & $5.23 \pm 0.45$ & $5.67 \pm 0.50$ & $0.00^{*}$ \\
\hline$S_{1}-T$ & $2.89 \pm 0.36$ & $3.23 \pm 0.37$ & $0.00^{*}$ \\
\hline ASW & $11.01 \pm 0.72$ & $10.90 \pm 0.99$ & 0.51 \\
\hline
\end{tabular}

$A S L$ anterior sacral length, $A S C L$ anterior sacrococcygeal length, $P S C L$ posterior sacrococcygeal length, ASC anterior sacral curvature length, PSC: posterior sacral curvature length, $A C C$ anterior coccygeal curvature length, $P C C$ posterior coccygeal curvature length, $L T L-1,2$, 3 lengths of transverse lines, IFHR-3, IFHL2, 3 right-left interforaminal height, ASW anterior sacral width, LRFA-S the distance between left and right auricular surface, $S_{1}-S_{1} S_{1}-T: S 1$ sagittal and transverse vertebrae length, $S D$ standard deviation; ${ }^{*} p<0.05$ 
Table 6 The comparison of the mean values of the parameters that did not exhibit normal distribution

\begin{tabular}{llll}
\hline Parameters & $\begin{array}{l}\text { Female } \\
\text { Median (Min-Max) }\end{array}$ & $\begin{array}{l}\text { Male } \\
\text { Median (Min-Max) }\end{array}$ & PMWU \\
\hline PSL & 10.68 & 11.02 & $\mathbf{0 . 0 0 *}$ \\
& $(8.40-12.45)$ & $(9.63-13.10)$ & \\
SA & 17.53 & 21.50 & $\mathbf{0 . 0 0 *}$ \\
& $(12.50-24.38)$ & $(17.49-30.21)$ & \\
CA & 3.65 & 3.40 & 0.70 \\
& $(2.23-4.84)$ & $(2.25-5.89)$ & \\
LTL-4 & 2.47 & 2.59 & $\mathbf{0 . 0 0 *}$ \\
& $(1.67-2.83)$ & $(0.88-3.29)$ & \\
IFHR-1 & 1.32 & 1.35 & 0.67 \\
& $(0.94-1.75)$ & $(1.03-2.14)$ & \\
IFHR-2 & 0.86 & 0.88 & 0.08 \\
& $(0.39-1.39)$ & $(0.54-2.53)$ & \\
IFHL-1 & 1.40 & 1.36 & 0.81 \\
& $(0.84-2.71)$ & $(0.99-2.39)$ & \\
\hline
\end{tabular}

PSL posterior sacral length, SA sacral area, CA coccygeal area, LTL-4 length of transverse line 4, IFHR-1, 2, IFHL-1 right-left interforaminal height, median (minmax), MWU Mann-Whitney U; ${ }^{*} \mathrm{p}<0.05$

person at a time, as a way of determining whether it is well classified. This provides an unbiased estimate of the percentage of individuals who are misclassified (Gonzalez et al. 2009). 90.0\% of cross-validated grouped cases were correctly classified (Table 11).

\section{Discussion}

Sex estimation is the key procedure in forensic anthropology (Ubelaker and DeGaglia 2020). When morphological properties change, sex estimation becomes difficult. There is difficulty in sex estimation of missing, damaged, or fragmented remains that may result from mass disasters such as plane accidents, explosions, war, fire, or physical violence (Torimitsu et al. 2015). Osteometric standards regarding sex estimation differed

Table $7 \mathrm{ROC}$ analysis results for sagittal plane parameters

\begin{tabular}{lllllll}
\hline & Area & SE & Sen & Spe & Acc & $\mathbf{p}$ \\
\hline ASL & 0.63 & 0.06 & 0.36 & 0.90 & 0.63 & $\mathbf{0 . 0 3}$ \\
PSL & 0.68 & 0.05 & 0.58 & 0.72 & 0.65 & $\mathbf{0 . 0 0}$ \\
ASCL & 0.66 & 0.05 & 0.42 & 0.88 & 0.65 & $\mathbf{0 . 0 0}$ \\
PSCL & 0.72 & 0.05 & 0.50 & 0.88 & 0.69 & $<\mathbf{0 . 0 0}$ \\
ASC & 0.69 & 0.05 & 0.46 & 0.88 & 0.67 & $\mathbf{0 . 0 0}$ \\
PSC & 0.71 & 0.05 & 0.78 & 0.56 & 0.67 & $<0.00$ \\
ACC & 0.63 & 0.06 & 0.52 & 0.78 & 0.65 & $\mathbf{0 . 0 3}$ \\
PCC & 0.60 & 0.06 & 0.68 & 0.50 & 0.59 & 0.08 \\
SA & 0.88 & 0.03 & 0.80 & 0.84 & 0.82 & $<\mathbf{0 . 0 0}$ \\
CA & 0.52 & 0.06 & 0.50 & 0.66 & 0.58 & 0.71
\end{tabular}

$A S L, P S L$ anterior and posterior sacral length, $A S C L, P S C L$ anterior and posterior sacrococcygeal length, ASC, PSC anterior and posterior sacral curvature length, $A C C, P C C$ anterior and posterior coccygeal curvature length, $S A$ sacral area, $C A$ coccygeal area, Sen sensitivity, Spe specificity, Acc accuracy, SE standard error
Table $8 \mathrm{ROC}$ analysis results for coronal plane parameters

\begin{tabular}{lllllll}
\hline & Area & SE & Sen & Spe & Acc & $\mathbf{p}$ \\
\hline LTL-1 & 0.67 & 0.05 & 0.58 & 0.76 & 0.67 & $\mathbf{0 . 0 0}$ \\
LTL-2 & 0.77 & 0.05 & 0.74 & 0.74 & 0.74 & $<\mathbf{0 . 0 0}$ \\
LTL-3 & 0.82 & 0.04 & 0.56 & 0.92 & 0.74 & $<\mathbf{0 . 0 0}$ \\
LTL-4 & 0.69 & 0.05 & 0.68 & 0.64 & 0.66 & $\mathbf{0 . 0 0}$ \\
IFHR-1 & 0.53 & 0.06 & 0.30 & 0.88 & 0.59 & 0.68 \\
IFHR-2 & 0.60 & 0.06 & 0.96 & 0.28 & 0.62 & 0.08 \\
IFHR-3 & 0.53 & 0.06 & 0.28 & 0.84 & 0.56 & 0.58 \\
IFHL-1 & 0.51 & 0.06 & 0.42 & 0.48 & 0.45 & 0.81 \\
IFHL-2 & 0.52 & 0.06 & 0.24 & 0.92 & 0.58 & 0.73 \\
IFHL-3 & 0.59 & 0.06 & 0.56 & 0.92 & 0.61 & 0.11
\end{tabular}

LTL lengths of transverse lines, IFHR right interforaminal height, IFHL left interforaminal height, Sen sensitivity, Spe specificity, Acc accuracy, SE standard error

depending on parameters such as genetic, environmental forces, and degree of sexual dimorphism related to profession and lifestyle. This shows that osteometric standards cannot be applied in different samples. In addition, populations can undergo secular changes. It is therefore necessary to create temporary representative skeleton collections for population-specific anthropological standards (Gaya-Sancho et al. 2018; Macaluso and Lucena 2014; Singh and Pathak 2013; Steyn and İşcan 2008; Zhan et al. 2018). Anatomists, forensic medicine specialists, and anthropologists constantly work to develop novel methods to describe the skeleton or to determine more precise identifications depending on different parts of the skeleton (Letterman 1941; Steyn and İşcan 2008; Turan et al. 2019). In cases where long bones, skull, or pelvic integrity are not preserved, sex should be predicted with other dimorphic structures. The sacrum is an important bone since it is both the continuation of the vertebra and the pelvic girdle bones. Thus, the present study was conducted to investigate the sex dimorphism in sacrum and coccyx (Gaya-Sancho et al. 2018; Hegazy 2013; Rusk and Ousley 2016; Torimitsu et al. 2015; Zech et al. 2012; Zhan et al. 2018). In the current study, sex was predicted with $94 \%$ accuracy.

It is known that morphological methods lead to shallow knowledge when compared to metric methods. The

Table 9 ROC analysis results for axial plane parameters

\begin{tabular}{lllllll}
\hline & Area & SE & Sen & Spe & Acc & p \\
\hline LRFA-S & 0.55 & 0.06 & 0.38 & 0.76 & 0.57 & 0.37 \\
S $_{1}$-S & 0.75 & 0.05 & 0.80 & 0.66 & 0.73 & $<\mathbf{0 . 0 0}$ \\
S $_{1}$-T & 0.75 & 0.05 & 0.82 & 0.60 & 0.71 & $<\mathbf{0 . 0 0}$ \\
ASW & 0.53 & 0.06 & 0.48 & 0.66 & 0.57 & 0.58 \\
\hline
\end{tabular}

LRFA-S the distance between the left and right auricular surface, $S_{1}-S_{1} S_{1}-T: 1$. sacral vertebra sagittal and transverse length, ASW anterior sacral width, Acc accuracy, SE standard error, Sen sensitivity, Spe specificity 


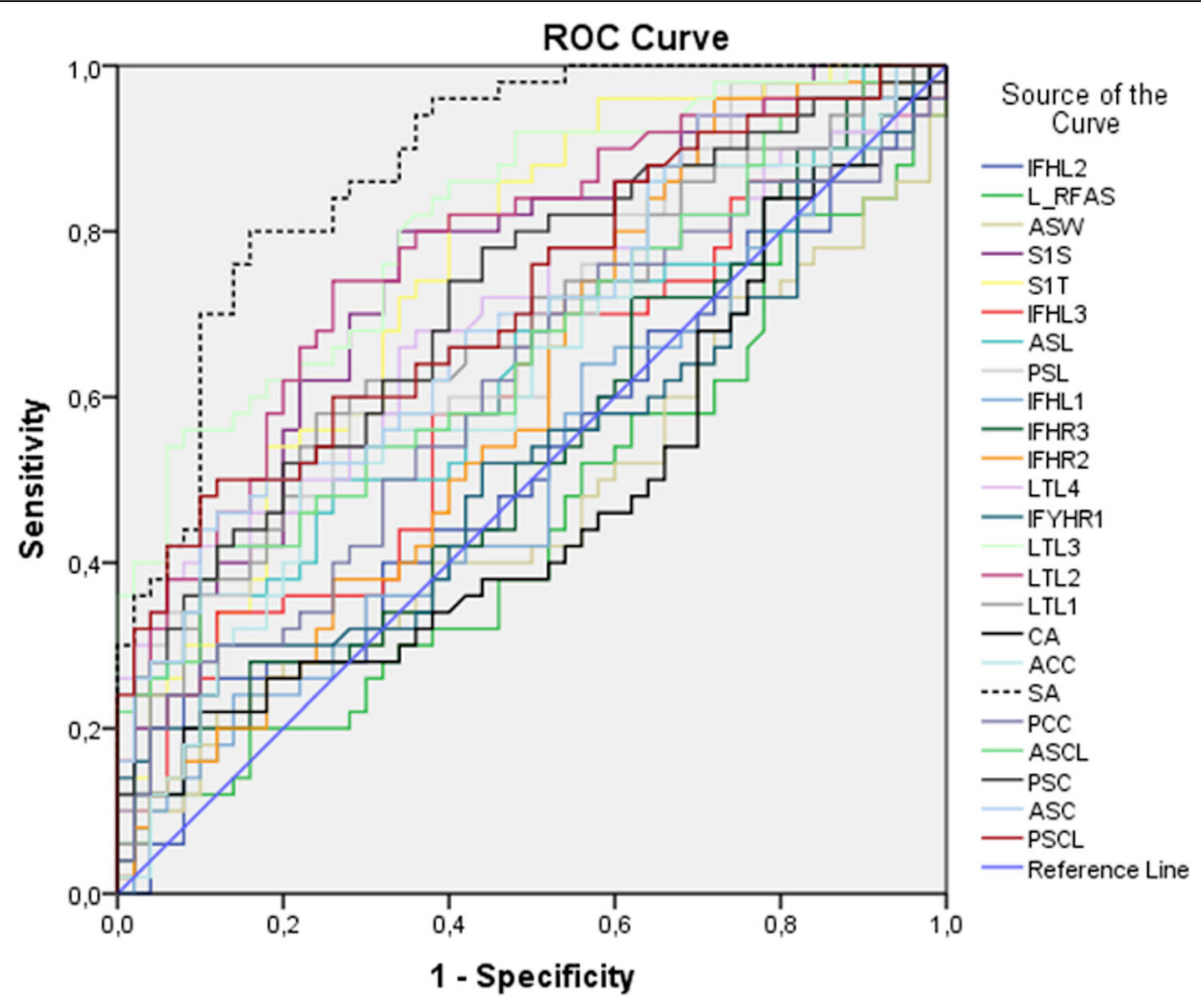

Fig. 5 Receiver operating characteristic curve (ROC) analysis result (ASL, PSL: anterior and posterior sacral length; ASCL, PSCL: anterior and posterior sacrococcygeal length; ASC, PSC: anterior and posterior sacral curvature length; ACC, PCC: anterior and posterior coccygeal curvature length; SA: sacral area; CA: coccygeal area; LTL-1,2,3,4: lengths of transverse lines; IFHR-1,2,3, IFHL-1,2,3: right-left interforaminal height; ASW: anterior sacral width; LRFA-S: the distance between left and right auricular surface; $\mathrm{S}_{1}-\mathrm{S}_{1} \mathrm{~S}_{1}-\mathrm{T}$ : S1 sagittal and transverse vertebrae length)

reliability is higher in metric methods (Etli et al. 2019; Krishan et al. 2016). Thus, metric methods were preferred in the present study. CT was employed to obtain cross-sectional images with high reliability, and since it allows fast and repeatable findings, and facilitates the collection of expert opinion from different locations concurrently. X-ray images are affected by the posture position of the person during the X-ray or diseases such as scoliosis. Another advantage of CT images is the ability to adjust the image on an orthogonal plane in a 3planar environment when compared to X-ray images (Hatch et al. 2014; Mamabolo et al. 2020; Michiue et al. 2018; Sidler et al. 2007; Torimitsu et al. 2015; Uldin 2017; Zech et al. 2012). However, by bringing the patient's images to the orthogonal plane in CT images, posture errors caused by the position are minimized. It provides the advantage of generalization both by measuring more parameters on CT images and by standardizing parameters in the orthogonal plane (Oner et al. 2019).

Studies conducted on the orthogonal plane are rare in the literature (Oner et al. 2019; Turan et al. 2019). The transformation into an orthogonal plane minimized orientation errors, and more accurate results were obtained in the study (Turan et al. 2019).

In this study, all parameters were measured by the same observer 3 times at different times (to minimize effects such as human error and muscle memory). TEM, rTEM, and R values (Table 4) were calculated for a total of 24 parameters. The $\mathrm{R}$ value for the 4 parameters was found between 0.71 and 0.79 and was interpreted as substantial significant. $\mathrm{R}$ values for the other 20 parameters were calculated between 0.80 and 1.00 , interpreted as almost perfect reliability (Jamaiyah et al. 2010; Perini et al. 2005). The reason for the high rTEM values in IFH parameters is because the average of the parameters is less than $1 \mathrm{~cm}$. We think that the reason for the high rTEM value of the CA parameter is due to the fact that the coccygeal vertebral number in individuals changes as 3-5. RTEM levels in other parameters are at acceptable levels (Perini et al. 2005).

The ASL parameter (Duman 2009; Etli et al. 2019; Gaya-Sancho et al. 2018; Zhan et al. 2018) and PSL, ASCL, and PSCL parameters were reported longer in males when compared to females in the present study and in similar studies (Etli et al. 2019; Torimitsu et al. 
Table 10 Discriminant function analysis

\begin{tabular}{|c|c|c|c|c|}
\hline Parameter & Unstandardized coefficient & $\begin{array}{l}\text { Fishers linear DF } \\
\text { Female }\end{array}$ & $\begin{array}{l}\text { Fishers linear DF } \\
\text { Male }\end{array}$ & Wilk's lambda \\
\hline$\overline{\mathrm{ASL}}$ & 0.42 & 52.19 & 53.61 & 0.93 \\
\hline PSL & -2.14 & -34.55 & -41.81 & 0.87 \\
\hline $\mathrm{ASCL}$ & -0.05 & -50.07 & -50.25 & 0.90 \\
\hline PSCL & 0.95 & 51.15 & 54.37 & 0.83 \\
\hline ASC & -0.52 & 6.06 & 4.29 & 0.87 \\
\hline PSC & 0.50 & 7.95 & 9.65 & 0.86 \\
\hline ACC & -0.15 & -8.58 & -9.09 & 0.95 \\
\hline PCC & 1.55 & -7.76 & -2.50 & 0.97 \\
\hline SA & 0.57 & -9.31 & -7.37 & 0.60 \\
\hline$C A$ & -1.95 & 12.12 & 5.51 & 0.99 \\
\hline LTL-1 & -1.56 & 35.40 & 30.12 & 0.90 \\
\hline LTL-2 & 1.63 & -24.07 & -18.53 & 0.78 \\
\hline LTL-3 & 1.20 & 26.83 & 30.89 & 0.70 \\
\hline LTL-4 & 0.18 & 12.07 & 12.68 & 0.93 \\
\hline IFHR-1 & -0.85 & 12.24 & 9.35 & 0.98 \\
\hline IFHR-2 & 1.01 & 14.12 & 17.54 & 0.95 \\
\hline IFHR-3 & -1.15 & 48.23 & 44.34 & 0.99 \\
\hline IFHL-1 & -0.42 & 3.06 & 1.65 & 0.99 \\
\hline IFHL-2 & 0.34 & -32.45 & -31.29 & 0.99 \\
\hline IFHL-3 & 0.66 & -67.71 & -65.49 & 0.97 \\
\hline LRFA-S & -0.98 & 21.87 & 18.54 & 0.99 \\
\hline$S_{1}-T$ & -0.04 & 14.38 & 14.24 & 0.82 \\
\hline$S_{1}-S$ & 0.25 & 8.39 & 9.25 & 0.81 \\
\hline ASW & 0.40 & 4.13 & 5.48 & 0.99 \\
\hline
\end{tabular}

DF discriminant function, ASL anterior sacral length, PSL posterior sacral length, $A S C L$ anterior sacrococcygeal length, PSCL posterior sacrococcygeal length, $A S C$ anterior sacral curvature length, $P S C$ posterior sacral curvature length, $A C C$ anterior coccygeal curvature length, $P C C$ posterior coccygeal curvature length, $S A$ sacral area, $C A$ coccygeal area, $L T L$ lengths of transverse lines, IFHR right interforaminal height, IFHL left interforaminal height, $L R F A-S$ the distance between the left and right auricular surface, S1-S, S1-T first sacral vertebra sagittal and transverse length, ASW anterior sacral width

Table 11 The classification results obtained with Fisher's linear discriminant analysis between the sexes

\begin{tabular}{|c|c|c|c|c|c|}
\hline \multicolumn{6}{|c|}{ Classification results $^{\mathrm{a}, \mathrm{c}}$} \\
\hline \multirow[t]{2}{*}{ Sex } & & & \multicolumn{2}{|c|}{$\begin{array}{l}\text { Predicted group } \\
\text { membership }\end{array}$} & \multirow[t]{2}{*}{ Total } \\
\hline & & & Female & Male & \\
\hline \multirow[t]{4}{*}{ Original } & Count & Female & 46 & 4 & 50 \\
\hline & & Male & 2 & 48 & 50 \\
\hline & $\%$ & Female & 92.0 & 8.0 & 100.0 \\
\hline & & Male & 4.0 & 96.0 & 100.0 \\
\hline \multirow[t]{4}{*}{ Cross-validated $^{\text {b }}$} & Count & Female & 46 & 4 & 50 \\
\hline & & Male & 6 & 44 & 50 \\
\hline & $\%$ & Female & 92.0 & 8.0 & 100.0 \\
\hline & & Male & 12.0 & 88.0 & 100.0 \\
\hline
\end{tabular}

${ }^{\mathrm{a}} 94.0 \%$ of original grouped cases correctly classified

${ }^{b}$ Cross-validation is done only for those cases in the analysis. In cross-

validation, each case is classified by the functions derived from all cases other than that case

${ }^{\mathrm{c}} 90.0 \%$ of cross-validated grouped cases were correctly classified
2017; Zhan et al. 2018), and it was observed that these parameters could be used in sex estimation (Tables 12 and 13).

Similarly, it was found that the ASC parameter was longer in males and could be used in sex estimation (Mishra et al. 2003; Zhan et al. 2018). The present study ASC parameter findings were consistent with the literature and were longer in males when compared to females. It was suggested that the ASC parameter could be used in sex identification. In the current study, it was determined that PSC was longer in males, and it was suggested that it could be beneficial in sex estimation. Literature review revealed no study where PSC was measured. We suggest that this parameter would contribute to similar studies in this field. In the study, longer sacrum ASL, PSL, ASC, and PSC length in males indicated that sacrum was longer in males.

Woon et al. and Marwan et al. calculated the coccygeal curvature length as the average of the ACC and PCC 
Table 12 Comparison of the ASL measurement to literature

\begin{tabular}{llll}
\hline Author & Measurement method & Number of cases & F/M \\
\hline Duman (2009) & $\mathrm{CT}$ & 46 & $\mathrm{M}$ \\
Zhan et al. (2018) & $\mathrm{CT}$ & 350 & $\mathrm{M}$ \\
Gaya-Sancho et al. (2018) & Caliper & 170 & $\mathrm{M}$ \\
Etli et al. (2019) & $\mathrm{CT}$ & 480 & $\mathrm{M}$ \\
In this study (2020) & $\mathrm{CT}$ & 100 & $\mathrm{M}$ \\
\hline
\end{tabular}

M: men are taller than women

length figures in their studies (Marwan et al. 2014; Woon et al. 2013). Woon et al. reported that the coccygeal curvature length was longer in males (Woon et al. 2013), while Marwan et al. reported that there was no difference depending on sex (Marwan et al. 2014). In the present study, ACC and PCC were measured separately, not depending on an average. It was observed that the ACC was longer in males when compared to females, and it was concluded that it could be used in sex estimation. There was no difference between the PCC figures depending on sex. We suggested that the difference between the findings could be due to the difference between the populations.

Literature review revealed no study where SA and CA were measured. In the present study, it has come to the conclusion that SA was greater in males. In the ROC analysis, it was observed that the SA had the highest AUC value (0.88) when compared to other parameters in sex estimation. This demonstrated that SA was the most dimorphic parameter when compared to other measurements conducted on the sacrum. We suggest that studies on the SA parameter would contribute to future studies. Although CA was greater in females, the difference was not significant.

Duman reported that LTL-1, 2, and 3 and IFHL-1 were longer in males when compared to females, while there were no differences between LTL-4; IFHR-1, 2, and 3; and IFHL-2 and 3 parameters depending on sex (Duman 2009). In the present study, it was concluded that LTL-1, 2, 3, and 4 were longer in males when compared to females, and there were no differences between IFHR-1, 2, and 3 and IFHL-1, 2, and 3 parameters depending on sex.
There are studies in the literature which reported that LRFA-S was longer in females when compared to males (Mishra et al. 2003; Zhan et al. 2018) and those that reported no difference depending on sex (Etli et al. 2019; Torimitsu et al. 2017). Similarly, there are studies which concluded that the ASW parameter was longer in females (Başaloğlu et al. 2005; Zhan et al. 2018). In the current study, although both LRFA-S and ASW were longer in females when compared to males, the difference was not significant.

Although there are studies in the literature which reported that the $S_{1}-S$ parameter was longer in males when compared to females (Etli et al. 2019; Torimitsu et al. 2017; Zhan et al. 2018), other studies (Başaloğlu et al. 2005; Duman 2009; Mishra et al. 2003) indicated that there was no difference depending on sex. Similarly, certain studies concluded that the $\mathrm{S}_{1}-\mathrm{T}$ was longer in males (Etli et al. 2019; Mishra et al. 2003; Torimitsu et al. 2017). Başaloğlu et al. reported that the $S_{1}-T$ parameter did not differ depending on sex (Başaloğlu et al. 2005). In the present study, it was determined that both $\mathrm{S}_{1}-\mathrm{S}$ and $\mathrm{S}_{1}$ - $\mathrm{T}$ were longer in males when compared to females. Thus, it was concluded that the base of the sacrum was larger in males (Table 14).

Although there are studies in the literature that employed ROC analysis in sex estimation (Bongiovanni and Spradley 2012; Ekizoglu et al. 2014; Oner et al. 2019; Ramadan et al. 2010; Spradley and Jantz 2011), the studies where ROC analysis was utilized on the sacrum for sex estimation are rare (Franklin et al. 2014; Hussein et al. 2016). In a study conducted by Hussein et al. on the Egyptian population, the accuracy of sex estimation with $S_{1}-T$ and $S_{1}-S$ parameters was $66 \%$ and $68.9 \%$,

Table 13 Comparison of the PSL, ASCL, and PSCL measurements to literature

\begin{tabular}{llll}
\hline Author & Measurement method & Number of cases & F/M \\
\hline Torimitsu et al. (2017) & CT, cadaver & 230 & M \\
Zhan et al. (2018) & CT & 350 & M \\
Etli et al. (2019) & CT & 480 & M \\
In this study (2020) & CT & 100 & $\mathrm{M}$ \\
\hline
\end{tabular}

M: men are taller than women 
Table 14 Comparison of the $S_{1}$-S measurement to literature

\begin{tabular}{llll}
\hline Author & Measurement method & Number of cases & F/M \\
\hline Mishra et al. (2003) & Caliper & 116 & $\mathrm{X}$ \\
Başaloğlu et al. (2005) & Caliper & 60 & $\mathrm{X}$ \\
Duman (2009) & $\mathrm{CT}$ & 46 & $\mathrm{X}$ \\
Torimitsu et al. (2017) & $\mathrm{CT}$, cadaver & 230 & $\mathrm{M}$ \\
Zhan et al. (2018) & $\mathrm{CT}$ & 350 & $\mathrm{M}$ \\
Etli et al. (2019) & $\mathrm{CT}$ & 480 & $\mathrm{M}$ \\
In this study (2020) & $\mathrm{CT}$ & 100 & $\mathrm{M}$ \\
\hline
\end{tabular}

M: men are taller than women, $X:$ there is no significant difference

respectively, and was $73 \%$ and $71 \%$ in the present study. Unlike the studies conducted by Hussein et al., a higher accuracy was obtained in sex estimation in the present study, since the current study was conducted with orthogonal adjustment. It was found that the sex estimation accuracy of LRFA-S was $50 \%$ in both studies. Since this is the same as the random probability of being a woman or a man, it has come to the conclusion that there was no single parameter that could predict sex $\left(\mathrm{S}_{1}\right.$ $\mathrm{T}_{\mathrm{AUC}}=0.652, \mathrm{~S}_{1}-\mathrm{S}_{\mathrm{AUC}}=0.609$, LRFA-S $\left.\mathrm{AUC}_{\mathrm{AUC}}=0.523\right)$ (Hussein et al. 2016). ROC analysis conducted in the present study demonstrated that SA, PSCL, ASC, PSC, LTL-2, LTL-3, and $\mathrm{S}_{1}-\mathrm{S}, \mathrm{S}_{1}-\mathrm{T}$ parameters had high diagnostic value in sex estimation $(0.5<\mathrm{AUC}<1.0)$. The parameter with the highest diagnostic value was SA (AUC = $0.88 /$ Acc $=82 \%$ ).

The accuracy of the results of the discriminant analysis conducted by Zech et al. on Caucasian subjects was $70.2 \%$ for males and $71.3 \%$ for females according to observer 1 and $70.2 \%$ for males and $70.9 \%$ for males according to observer 2 (Zech et al. 2012). In a study conducted on the Japanese population with stepwise discriminant analysis, the accuracy rate was determined as $81.7 \%$ for males, $85.2 \%$ for females, and $83.5 \%$ for all (Torimitsu et al. 2017). In a study conducted on the Chinese population, the accuracy rate with stepwise discriminant analysis was reported as $83.2 \%$ for males, $86.9 \%$ for females, and $84.9 \%$ for all (Zhan et al. 2018). Etli et al. found the same rate as $82.5 \%$ with linear discriminant analysis (Etli et al. 2019). The fact that the present study was conducted with 24 parameters (especially the SA parameter) led to a higher accuracy ( $94 \%$ for all) when compared to other studies.

\section{Conclusions}

Contrary to previous studies in the literature, it could be suggested that the present study, where a high accuracy (94\%) was reported with sacrum and coccyx measurements, may contribute to future studies on sex estimation. In the ROC analysis, it was observed that the SA had the highest AUC value (0.88) when compared to other parameters in sex estimation. This demonstrated that SA was the most dimorphic parameter when compared to other measurements conducted on the sacrum. In conclusion, this paper provides indications that the sacrum and coccyx are important bones for sex estimation and they could be effectively used as alternatives in forensic cases when the skull and pelvis are commingled, fragmented, or unavailable.

\section{Abbreviations \\ CT: Computed Tomography; ROC: Receiver Operating Characteristic; AUC: Area Under the Curve; Acc: Accuracy rate; Sen: Sensitivity; Spe: Specificity; MDCT: Multidetector Computerized Tomography; F: Female; M: Male; MPR: Multi-planar Reconstruction; MIP: Maximum Intensity Projection; ASL: Anterior Sacral Length; PSL: Posterior Sacral Length; ASCL: Anterior Sacrococcygeal Length; PSCL: Posterior Sacrococcygeal Length; ASC: Anterior Sacral Curvature Length; PSC: Posterior Sacral Curvature Length; ACC: Anterior Coccygeal Curvature Length; PCC: Posterior Coccygeal Curvature Length; SA: Sacral Area; CA: Coccygeal Area; LTL- 1: Length of transverse line 1; LTL-2: Length of transverse line 2; LTL- 3: Length of transverse line 3; LTL-4: Length of transverse line 4; IFHR-1: Right interforaminal height-1; IFHR-2: Right interforaminal height-2; IFHR-3: Right interforaminal height-3; IFHL-1: Left interforaminal height-1; IFHL-2: Left interforaminal height-2; IFHL-3: Left interforaminal height-3; LRFA-S: The distance between left and right auricular surface; S1-T: 1st sacral vertebra transverse length; S1-S: 1st sacral vertebra sagittal length; ASW: Anterior Sacral Width; SD: Standard Deviation; SE: Standard Error; TEM: Technical Error of Measurements; rTEM: Relative Technical Error of Measurements; \\ $\mathrm{R}$ : Coefficient of reliability}

\section{Acknowledgements}

No financial support has been received from any institution for this article. And additionally, we are grateful to our families.

\section{Authors' contributions}

OZ: Project development, data analysis, manuscript writing and editing. BRS: Data collection, formatting the manuscript, manuscript writing and editing.

OS: Data collection, data analysis, manuscript writing.

All authors read and approved the final version of the article.

\section{Funding}

No financial support has been received from any institution for this article.

Availability of data and materials

Not applicable. 


\section{Declarations}

\section{Ethics approval and consent to participate}

Ethics committee approval is available. The study was approved by the Karabuk University Non-Interventional Clinical Research Ethics Committee on 25/09/2019 with the protocol no: 6/10

\section{Consent for publication}

Since this study is retrospective, informed consent form was not used.

\section{Competing interests}

The authors declare that they have no competing interests.

\section{Author details}

${ }^{1}$ Faculty of Medicine Department of Anatomy, Karabuk University, Karabuk, Turkey. ${ }^{2}$ Faculty of Medicine Department of Radiology, Karabuk University, Karabuk, Turkey.

Received: 26 November 2020 Accepted: 24 June 2021

Published online: 05 July 2021

\section{References}

Başaloğlu H, Turgut M, Taşer F, Ceylan T, Başaloğlu H, Ceylan A (2005) Morphometry of the sacrum for clinical use. Surg Radiol Anat 27(6):467-471. https://doi.org/10.1007/s00276-005-0036-1

Bongiovanni R, Spradley MK (2012) Estimating sex of the human skeleton based on metrics of the sternum. Forensic Sci Int 219(1):290.e291-290.e297. https:// doi.org/10.1016/j.forsciint.2011.11.034

Case DT, Ross AH (2007) Sex determination from hand and foot bone lengths. J Forensic Sci 52(2):264-270. https://doi.org/10.1111/j.1556-4029.2006.00365.x

Chiba F, Makino Y, Torimitsu S, Motomura A, Inokuchi G, Ishii N, Hoshioka Y, Abe H, Yamaguchi R, Sakuma A (2018) Sex estimation based on femoral measurements using multidetector computed tomography in cadavers in modern Japan. Forensic Sci Int 292:262. e261-262. e266. https://doi.org/10.1 016/j.forsciint.2018.09.027

Curate F, Coelho J, Gonçalves D, Coelho C, Ferreira MT, Navega D, Cunha E (2016) A method for sex estimation using the proximal femur. Forensic Sci Int 266:579. e571-579. e577. https://doi.org/10.1016/j.forsciint.2016.06.011

Dedouit F, Savall F, Mokrane F, Rousseau H, Crubézy E, Rougé D, Telmon N (2014) Virtual anthropology and forensic identification using multidetector CT. Br J Radiol 87(1036):20130468. https://doi.org/10.1259/bjr.20130468

Duman T (2009) Yetişkinlerde Os Sacrum'un Çok Kesitli Bilgisayarlı Tomografi (ÇKBT) ile morfometrik incelenmesi, Master dissertation. Selçuk Üniversitesi Sağık Bilimleri Enstitüsü

Ekizoglu O, Hocaoglu E, Inci E, Bilgili MG, Solmaz D, Erdil I, Can IO (2014) Sex estimation from sternal measurements using multidetector computed tomography. Medicine 93(27):e240-e240. https://doi.org/10.1097/MD. 0000000000000240

Ekizoglu O, Hocaoglu E, Inci E, Can IO, Solmaz D, Aksoy S, Buran CF, Sayin I (2016) Assessment of sex in a modern Turkish population using cranial anthropometric parameters. Legal Med 21:45-52. https://doi.org/10.1016/j. legalmed.2016.06.001

Etli Y, Asirdizer M, Hekimoglu Y, Keskin S, Yavuz A (2019) Sex estimation from sacrum and coccyx with discriminant analyses and neural networks in an equally distributed population by age and sex. Forensic Sci Int 303:109955. https://doi.org/10.1016/j.forsciint.2019.109955

Franklin D, Cardini A, Flavel A, Marks MK (2014) Morphometric analysis of pelvic sexual dimorphism in a contemporary Western Australian population. Int J Legal Med 128(5):861-872. https://doi.org/10.1007/s00414-014-0999-8

Gaya-Sancho B, Aguilera IA, Navarro-Muñoz JJ, López MB (2018) Sex determination in a Spanish population based on sacrum. J Forensic Legal Med 60:45-49. https://doi.org/10.1016/j.jflm.2018.10.001

Gonzalez PN, Bernal V, Perez SI (2009) Geometric morphometric approach to sex estimation of human pelvis. Forensic Sci Int 189(1-3):68-74. https://doi.org/1 0.1016/j.forsciint.2009.04.012

Grabherr S, Cooper C, Ulrich-Bochsler S, Uldin T, Ross S, Oesterhelweg L, Bolliger S, Christe A, Schnyder P, Mangin P (2009) Estimation of sex and age of "virtual skeletons"-a feasibility study. Eur Radiol 19(2):419-429. https://doi. org/10.1007/s00330-008-1155-y
Hatch GM, Dedouit F, Christensen AM, Thali MJ, Ruder TD (2014) RADid: a pictorial review of radiologic identification using postmortem CT. J Forensic Radiol Imaging 2(2):52-59. https://doi.org/10.1016/j.jofri.2014.02.039

Hegazy A (2013) Sex assessment of the first sacral vertebra, MRI study. J Am Sci $9(10)$

Hemy N, Flavel A, Ishak N-I, Franklin D (2013) Sex estimation using anthropometry of feet and footprints in a Western Australian population. Forensic Sci Int 231(1-3):402. e401-402. e406. https://doi.org/10.1016/j. forsciint.2013.05.029

Hussein RF, Shokry DA, Ismail MM, Abd-Elsatar MH, Ibrahim SF (2016) Sex Identification from radyologic anthropometry of sacral and fifth lumbar vertebral measurements. Egypt J Forensic Sci Appl Toxicol 16(2):117-126. https://doi.org/10.21608/ejfsat.2016.41018

Issa SY, Khanfour AA, Kharoshah M (2016) A model for stature estimation and sex prediction using percutaneous ulnar and radial lengths in autopsied adult Egyptians. Egypt J Forensic Sci 6(2):84-89. https://doi.org/10.1016/j.ejfs.2016. 05.013

Jamaiyah H, Geeta A, Safiza M, Khor G, Wong N, Kee C, Rahmah R, Ahmad AZ, Suzana S, Chen W (2010) Reliability, technical error of measurements and validity of length and weight measurements for children under two years old in Malaysia. Med J Malaysia 65(Suppl A):131-137

Karakas HM, Celbis O, Harma A, Alicioglu B (2011) Total body height estimation using sacrum height in Anatolian Caucasians: multidetector computed tomography-based virtual anthropometry. Skelet Radiol 40(5):623-630. https://doi.org/10.1007/s00256-010-0937-x

Krishan K, Chatterjee PM, Kanchan T, Kaur S, Baryah N, Singh R (2016) A review of sex estimation techniques during examination of skeletal remains in forensic anthropology casework. Forensic Sci Int 261:165. e161-165. e168. https://doi. org/10.1016/j.forsciint.2016.02.007

Letterman GS (1941) The greater sciatic notch in American whites and Negroes. Am J Phys Anthropol 28(1):99-116. https://doi.org/10.1002/ajpa.1330280106

Macaluso PJ, Lucena J (2014) Estimation of sex from sternal dimensions derived from chest plate radiographs in contemporary Spaniards. Int J Legal Med 128(2):389-395. https://doi.org/10.1007/s00414-013-0910-z

Mamabolo B, Alblas A, Brits D (2020) Modern imaging modalities in forensic anthropology and the potential of low-dose X-rays. Forensic Imaging 23: 200406. https://doi.org/10.1016/j.fri.2020.200406

Marino EA (1995) Sex estimation using the first cervical vertebra. Am J Phys Anthropol 97(2):127-133. https://doi.org/10.1002/ajpa.1330970205

Marlow EJ, Pastor RF (2011) Sex determination using the second cervical vertebra-a test of the method. J Forensic Sci 56(1):165-169. https://doi. org/10.1111/j.1556-4029.2010.01543.x

Marwan YA, Al-Saeed OM, Esmaeel AA, Kombar ORA, Bendary AM, Azeem MEA (2014) Computed tomography-based morphologic and morphometric features of the coccyx among Arab adults. Spine 39(20):E1210-E1219. https:// doi.org/10.1097/brs.0000000000000515

Michiue T, Hishmat AM, Oritani S, Miyamoto K, Amin MF, Ishikawa T, Maeda H (2018) Virtual computed tomography morphometry of the patella for estimation of sex using postmortem Japanese adult data in forensic identification. Forensic Sci Int 285:206. e201-206. e206. https://doi.org/10.101 6/j.forsciint.2017.11.029

Mishra S, Singh P, Agrawal A, Gupta R (2003) Identification of sex of sacrum of Agra region. J Anat Soc India 52

Oner Z, Oner S, Kurtul I, Sahin B (2019) Usage length of sternum components and sternal angle through images obtained by computerized tomography image reconstruction in gender determination. J Turgut Ozal Med Center 26(1):1. https://doi.org/10.5455/annalsmedres.2018.11.257

Papaioannou VA, Kranioti EF, Joveneaux P, Nathena D, Michalodimitrakis M (2012) Sexual dimorphism of the scapula and the clavicle in a contemporary Greek population: applications in forensic identification. Forensic Sci Int 217(1-3): 231. e231-231. e237. https://doi.org/10.1016/j.forsciint.2011.11.010

Perini TA, de Oliveira GL, Ornellas JS, de Oliveira FP (2005) Technical error of measurement in anthropometry. Rev Bras Med Esporte 11(1):81-85. https:// doi.org/10.1590/\$1517-86922005000100009

Ramadan SU, Türkmen N, Dolgun NA, Gökharman D, Menezes RG, Kacar M, Koşar $U$ (2010) Sex determination from measurements of the sternum and fourth rib using multislice computed tomography of the chest. Forensic Sci Int 197(1-3):120. e121-120. e125. https://doi.org/10.1016/j.forsciint.2009.12.049

Rusk K, Ousley SD (2016) An evaluation of sex-and ancestry-specific variation in sacral size and shape using geometric morphometrics. Am J Phys Anthropol 159(4):646-654. https://doi.org/10.1002/ajpa.22926 
Sidler M, Jackowski C, Dirnhofer R, Vock P, Thali M (2007) Use of multislice computed tomography in disaster victim identification-advantages and limitations. Forensic Sci Int 169(2-3):118-128. https://doi.org/10.1016/j. forsciint.2006.08.004

Singh J, Pathak R (2013) Morphometric sexual dimorphism of human sternum in a north Indian autopsy sample: sexing efficacy of different statistical techniques and a comparison with other sexing methods. Forensic Sci Int 228(1-3):174. e171-174. e110. https://doi.org/10.1016/j.forsciint.2013.03.020

Šlaus M, Bedić Ž, Strinović D, Petrovečki V (2013) Sex determination by discriminant function analysis of the tibia for contemporary Croats. Forensic Sci Int 226(1-3): 302. e301-302. e304. https://doi.org/10.1016/j.forsciint.2013.01.025

Spradley MK, Jantz RL (2011) Sex estimation in forensic anthropology: skull versus postcranial elements. J Forensic Sci 56(2):289-296. https://doi.org/10.1111/j.1 556-4029.2010.01635.x

Steyn M, Isscan M (2008) Metric sex determination from the pelvis in modern Greeks. Forensic Sci Int 179(1):86. e81-86. e86. https://doi.org/10.1016/j. forsciint.2008.04.022

Torimitsu S, Makino Y, Saitoh H, Sakuma A, Ishii N, Yajima D, Inokuchi G, Motomura A, Chiba F, Yamaguchi R (2015) Morphometric analysis of sex differences in contemporary Japanese pelves using multidetector computed tomography. Forensic Sci Int 257:530. e531-530. e537. https://doi.org/10.101 6/j.forsciint.2015.10.018

Torimitsu S, Makino Y, Saitoh H, Sakuma A, Ishii N, Yajima D, Inokuchi G, Motomura A, Chiba F, Yamaguchi R (2017) Sex determination based on sacral and coccygeal measurements using multidetector computed tomography in a contemporary Japanese population. J Forensic Radiol Imaging 9:8-12. https://doi.org/10.1016/j.jofri.2017.01.001

Torimitsu S, Makino Y, Saitoh H, Sakuma A, Ishii N, Yajima D, Inokuchi G, Motomura A, Chiba F, Yamaguchi R (2018) Sex assessment based on clavicular measurements in a modern Japanese population using multidetector computed tomography. Forensic Sci Int 285:207. e201-207. e205. https://doi.org/10.1016/j.forsciint.2017.10.009

Turan MK, Oner Z, Secgin Y, Oner S (2019) A trial on artificial neural networks in predicting sex through bone length measurements on the first and fifth phalanges and metatarsals. Comput Biol Med 115:103490. https://doi.org/1 0.1016/j.compbiomed.2019.103490

Ubelaker DH, DeGaglia CM (2020) Factors of population variation in sex estimation methodology. In: Sex Estimation of the Human Skeleton. Elsevier, pp 281-293

Uldin T (2017) Virtual anthropology - a brief review of the literature and history of computed tomography. Forensic Sci Res 2(4):165-173. https://doi.org/10.1 080/20961790.2017.1369621

Woon JT, Perumal V, Maigne J-Y, Stringer MD (2013) CT morphology and morphometry of the normal adult coccyx. Eur Spine J 22(4):863-870. https:// doi.org/10.1007/s00586-012-2595-2

Zech W-D, Hatch G, Siegenthaler L, Thali MJ, Lösch S (2012) Sex determination from os sacrum by postmortem CT. Forensic Sci Int 221(1-3):39-43. https:// doi.org/10.1016/j.forsciint.2012.03.022

Zhan M-J, Fan F, Qiu L-R, Peng Z, Zhang K, Deng Z-H (2018) Estimation of stature and sex from sacrum and coccyx measurements by multidetector computed tomography in Chinese. Legal Med 34:21-26. https://doi.org/10.1016/j.lega Imed.2018.07.003

\section{Publisher's Note}

Springer Nature remains neutral with regard to jurisdictional claims in published maps and institutional affiliations.

\section{Submit your manuscript to a SpringerOpen ${ }^{\circ}$ journal and benefit from:}

- Convenient online submission

- Rigorous peer review

- Open access: articles freely available online

- High visibility within the field

- Retaining the copyright to your article

Submit your next manuscript at $\boldsymbol{\nabla}$ springeropen.com 